\title{
O RESGATE DAS RAIZES - A INFLUÊNCIA DA FORMAÇÃO FAMILIAR E SOCIAL NA ESCOLHA E EXERCÍCIO DA ENFERMAGEM *
}

\author{
Maria Itayra Coelho de Souza Padilha**
}

\begin{abstract}
RESUMO - O estudo trata da análise da influência familiar e social na escolha e exercício de enfermagem, pretendendo-se traçar um perfil familiar, identificar e analisar a exis:inncia de atitudes de dominação/submissão no contexto profissional. É quanti-qualitativo, utiliza o materialismo histórico na abordagem metodológica. Consta de 117 enfermeiras, 2 instrumentos, um formulário e um roteiro de entrevista. Provêm de famflias grandes onde o pai exerce o pátrio poder e a mãe as tarefas domésticas. Estereótipos sexistas determinam a escolha e exercício profissional feminino. Consideram o homem mais preparado para o poder decisório. Família influencia na relação com colegas e clientela. Divisão de tarefas domésticas pouco compartilhadas com marido exercendo dupla jornada de trabalho.
\end{abstract}

ABSTRACT - This study concerns the investigation of the social and family influences on the choice and professional practice of nursing, having as objectives to establish a family profile and to identity and to analyse the existing domination/submission attitudes in the professional environment. This study is quanti-qualitative and it uses the historical materialism in the methodological approach. It consists of 117 nurses and 2 instruments, a question form and interview guidelines. The nurses come from large families where the father has the paternal power and the mother is in charge of the domestic tasks. Sexual stereotypes determine the choice and professional practice by women. Men are considered better qualified to have the decision power. The family has influence in the relationship with colleagues and patients. The husband takes part in only of few domestic tasks generating double working time journey work.

\section{INTRODUÇÃO}

Este trabalho originou-se das reflexões da autora sobre a situação social da mulher na sociedade e principalmente, no exercício da profissão - enfermagem, onde segundo dados do COFEn ${ }^{8}$ representa $94,1 \%$ do total de profissionais do país.

Examinando a literatura sobre o assunto, verifica-se uma preocupação crescente em analisar a enfermagem através dos processos histórico, político, cultural, educativo e trabalhista, correlacionando-os com a problemática da mulher. Esses estudos, além de servirem de subsídios para políticas públicas em diferentes setores que afetam diretamente a mulher, são importantes para produzir conhecimento a respeito delas mesmas e de sua própria história.

CORADINI ${ }^{12}$ reitera esta afirmação quando diz que se abre um novo caminho para as enfermeiras no momento em que a mulher se volta para as suas origens e reavalia os padrões que lhe foram pré-estabelecidos, descobrindo novas formas de ação, tanto no campo profissional, como pessoal.

Verifica-se que de um lado houve um enorme avanço na discussão desse tema. De outro lado avidencia-se, conforme análise de BATISTA $^{3}$ que há baixa incidência de pesquisas referentes a "crenças, atitudes, comportamentos e necessidades em saúde".

Esse fato coincide com o que percebemos ao fazer a revisão bibliográfica sobre os fatores intervenientes na escolha e exercício da enfermagem, principalmente aqueles relacionados às questões familiares e sociais, bem como, sobre as atitudes de dominação/submissão/exploração, vividas pelas enfermeiras nas instituiçōes onde exercem a profissão.

A Enfermeira como pessoa e como profissional pertence a um sistema social, conseqüentemente, está inserida em uma cultura, estruturada dentro de acontecimentos histórico-sociais que não podem de forma alguma serem desvinculados ou ignorados para não correr o risco de perder a identidade.

Para saber quem somos, onde estamos e para onde vamos, temos que investigar as raízes de nossa história. Investigação esta que não atenha apenas à historia formal, mas considere principalmente a historia pessoal, que juntas compõem o coletivo social. Através deste conhecimento é que podemos compreender o engajamento da realidade de cada pessoa, na formação de valores da sociedade.

\footnotetext{
* Artigo baseado em Tese de Livre Docencia do mesmo nome defendida em 1991 na Escola de Enfermagem Alfredo Pinto UNI-RIO

** Professora Assistente do Departamento de Metodologia da Enfermagem da Escola de Enfermagem Anna Nery da Universidade Federal do Rio de Janeiro. Mestre em Enfermagem pela EEAN-UFRJ.
} 
Na prática profissional observamos, muitas vezes, as atitudes das enfermeiras diante do médico como de obediência e submissão às "ordens médicas", ausência de uma atitude questionadora e científica, bem como, dificuldade ou quase inexistência de cooperação entre os elementos da equipe multiprofissinal. Em contrapartida, quando se refere à equipe de enfermagem verifica-se um revestimento grande de autoridade, responsabilidade e exigência no cumprimento dos deveres. E nos perguntamos, por que? De que decorrem estas atitudes? Do fato de ser mulher, historicamente submetida ao poder masculino ou a algo específico da profissão?

No trabalho desenvolvido por CASTRO ${ }^{9}$ relativo às dificuldades na incorporação dos resultados de pesquisa na prática de enfermagem, umas das conclusões foi a de que:

"a maior parte do grupo reproduz na vida profissional, o modelo de acomodação em que foi criado, reforçado posteriormente, durante a formação nas escolas de enfermagem".

Coloca-se em ponto de discussão a famnia, considerando que $\varepsilon$ nesta que a criança recebe orientação e estímulo para ocupar um determinado espaço na sociedade, em função de seu sexo, raça, crenças religiosas e status econômico e social.

Marido e mulher exercem funções diversas e complementares. O marido tem o papel de elo de ligação entre a família e o meio social, e de provedor de bens materiais, cabendo a esposa e mãe a criação dos filhos e o cuidado do lar.

PRADO $^{21}$ afirma que esta bipolaridade de papéis em função do sexo $\varepsilon$ determinante fundamental para a formação da personalidade tanto do menino, quanto da menina.

A ênfase maior está na sociedade patriarcal que, por si sర, não determina apenas uma forma de familia, baseada no parentesco masculino e no poder paterno, mas também toda estrutura social que nasça do poder do patriarca, instituindo, conforme LARGUIA $^{16}$, a macroformação social, que divide a sociedade em classes e dá origem às primeiras formas de opressão simbólica, através da submissão da mulher.

Em análise relativa à família no século XIX no estado de São Paulo, SAMARA ${ }^{22}$ ressalta que o chefe do clã ou grupo de parentes cuidava dos negócios e tinha, por princípio, preservar a linhagem e a honra da família, exercendo sua autoridade sobre a mulher e demais dependentes, sob a área de sua influência; sendo que estas deveriam ficar em casa cuidando dos filhos e das atividades domésticas.

Embora não tão evidente nos dias de hoje, nas famílias tradicionais ainda subsiste a idéia de que a mulher deve ser condicionada a assumir os papéis de esposa e mãe, colocando-os à frente de seus interesses individuais. Sendo assim, refere MICHEL ${ }^{18}$, deve procurar uma carreira condizente com a sua condição "feminina" como: "professora primária, secretária, enfermeira, etc.", que são menos qualificadas e competitivas no mercado de trabalho.

Quanto ao menino, sua socialização $\varepsilon$ feita visando dar-lhe uma profissão. O nepotismo familiar é conhecido em áreas políticas e da saúde. Verdadeiras dinastias se criam em certas profissões. De pai para filho perpetuam-se o acesso ds universidades e aos diversos cargos.
Os estere6tipos sexistas ocorrem desde a infância ao longo da vida, com uma série de comportamentos definidos, que obrigam tanto a mulher quanto o homem a uma luta constante pela libertação. Os meios de comunicação veiculam constantemente esterétipos sexistas, colocando a mulher como "estrela do lar", em posições subalternas ou objeto de prazer, enquanto que o homem aparece ocupando papéis importantes no trabalho e no corpo social.

$\mathrm{Na}$ enfermagem encontramos inúmeros exemplos de estere6tipos, nos quais são descritos o que se espera de uma enfermeira, isto $\hat{e}$, que seja "bondosa, dedicada, caridosa, abnegada, odebiente, servil, etc." Estas características nada mais são do que aquelas esperadas pelos pais, maridos, patrões, etc., como também fazem-nos reportar a história da enfermagem e ao cunho religioso da profissão.

As mulheres aparecem, desenvolvendo ações de cuidado aos doentes no trabalho caritativo das religiosas, parteiras leigas, provedoras de saúde à famnlia, e como voluntárias na assistência aos doentes, como foi o caso no Brasil, de Francisca de Sande e Anna Nery.

Desde meados do século passado, estas iniciam o desenvolvimento de ações de saúde de forma institucionalizada, quando as religiosas assumiram a responsabilidade do serviço de enfermagem nas Santas Casas de Misericórdia, conforme relata ALCÂNTARA ${ }^{1}$.

No dizer de PRADO ${ }^{21}$, tudo o que toca a vida orgânica da família, conta com o apoio e é controlado pela religião. Em troca, a instituição religiosa é sustentada pela familia que lhe fornece apoio institucional, colaborando de forma primordial ầ transmissão das crenças, ao cumprimento das práticas religiosas, à aceitação das punições impostas. Também GRELA ${ }^{13}$, analisando o assunto, relata que é através da opressão da sexualidade feminina, que a religião exerce maior poder.

Verifica-se que um dos fatores que influenciam na problemática das relações de trabalho, de conflito interprofissional e de subordinação da enfermagem ao médico é originada da socialização patriarcal e da religiosidade feminina.

$\mathrm{O}$ papel social de subordinação reservado às mulheres na esfera privada/doméstica se estende à esfera pública/profissional porque a maior parte do fazer em enfermagem reproduz as atividades da vida privada $\mathrm{e}$ que são essenciais à sobrevivência humana.

As mulheres permanecem no espaço pré-cívico e pré-político, aceitando as características que o patriarcado lhes legou durante séculos e séculos, exercendo o papel de coadjuvante na peça onde o papel político principal Ł́ executado pelo homem.

A hipótese de que a mulher atual, de uma forma ou de outra, faz a escolha profissional, influenciada pela história familiar e social que traz consigo, reflete a sua socialização para exercer os "papéis femininos" no exercício da enfermagem.

Estes papéis se apresentam na maioria das vezes como estereotipos comportamentais de "ser mulher" $\mathrm{e}$ de "ser enfermeira".

$\mathrm{O}$ condicionamento de inferioridade interiorizado pela menina, desde a infância, leva a enfermeira a reproduzir na vida profissional os papéis para os quais foi socializada, impedindo-a de crescer individualmente e coletivamente.

Assim, na situação de trabalho, parte das enfer- 
meiras interage com os outros componentes da equipe de saúde, permeada de comportamentos submissos que geram conflitos e que necessitam ser analisados.

Neste estudo, tentaremos buscar respostas referentes às influências da formação familiar e social na escolha e no exercício profissional e a forma como estes fatores estão interligados; julga-se de fundamental importância estabelecer uma conexão entre estes aspectos e as atitudes de dominação/submissão da mulher/enfermeira nos contextos da familia, da cidadania, do trabalho e da mundialidade.

Acreditamos que este trabalho abrirá mais um caminho para a discussão do papel da mulher na sociedade e da enfermeira na equipe de saúde, contribuindo com isso para o exercício da enfermagem edificante e a valorização das enfermeiras e dos enfermeiros dentro do grupo social e profissional.

\section{OBJETIVOS:}

1) Traçar um perfil familiar dos atores sociais que fazem parte da pesquisa.

2) identificar como as enfermeiras percebem a influência de sua formação familiar e social na escolha e exercício profissional.

3) Analisar a existência de atitudes de dominação/submissão no contexto profissional decorrentes da formação familiar e social.

\section{METODOLOGIA}

Foi utilizada a pesquisa quantiqualitativa, a fim de que pudesse aliar precisão e objetividade com a subjetividade daqueles dados relativos a valores intrínsecos do ser humano.

\section{Análise Quantitativa Descritiva}

Corpo Social* - Para atender aos objetivos deste estudo foi selecionado um hospital universitário federal, de atendimento geral, de grande porte, na cidade do Rio de Janeiro. O corpo social do hospital é multidisciplinar** tendo sido escolhido o grupo de profissionais de enfermagem graduados, devido a ser este o maior contingente de profissionais do hospital, num total de 256 e por ser a nossa área de interesse e domínio.

Grupo Amostral - Para a análise quantitativa utilizou-se $51,76 \%$ do total dos elementos do sexo feminino, o que corresponde a 117 (cento e dezessete) atores sociais. O tipo de amostra foi a probalística simples, isto $e$, enumerou-se na escala de pessoal do mês de julho, todas as enfermeiras que preenchessem os critérios de seleção da amostra. Em seguida sortearam-se as 117 para comporem a mesma.

Instrumento - Para a coleta de dados quantita- tivos foi utilizado 01 (um) instrumento. É um formulário contendo 29 (vinte e nove) questões abertas e fechadas das quais, 04 (quatro) referem-se a dados familiares, 06 (seis) sobre escolha profissional, 05 (cinco) sobre exercício profissional e 14 (quatorze) sobre o perfil dos componentes amostrais.

Esse instrumento foi elaborado a fim de que os seus resultados pudessem servir de subsídios para um diagnóstico preliminar da situação estudada e para a partir dele elaborar o roteiro de entrevista para prosseguimento da análise qualitativa.

Coleta de Dados - O formulário foi validado por um grupo de 10 (dez) enfermeiras não pertencentes ao universo em questão. Após revisão necessária, os formulários foram aplicados individualmente para cada Enfermeira selecionada nas Unidades de tabalho, nos horários de trabalho das mesmas, pela própria pesquisadora e contou com o auxílio de duas (2) enfermeiras da instituição em estudo.

O período de coleta de dados do formulário ocorreu de 02 de julho a 02 de agosto de 1990.

Tratamento Estatístico - O tratamento estatístico escolhido foi o de análise por frequiência simples e percentual, principalmente pelo fato de a amostra conter grande número de elementos. Este método permite efetuar medidas de intensidade e importância. S6 serão tratados estatisticamente nestes estudos, aqueles dados de relevância para análise e discussão dos resultados.

\section{Análise Qualitativa do Grupo Amostral}

Método - Análise de Conteúdo

Construção do Instrumento - Roteiro de entrevista semi-estruturada, dividido em quatro partes: Infância, Adolescência, Juventude/Maturidade e Repetição de Atitudes Familiares e/ou Sociais no Exercício Profissional.

Realização das Entrevistas - Após seleção internacional dos atores social, foram realizadas 13 (treze) entrevistas pela pesquisadora, no período de 05 a 28 de setembro de 1990 . Os locais e os horários foram de escolha das entrevistadas, sendo que 10 (dez) escolheram suas proprias unidades de trabalho em sala reservada e 03 (três) preferiram sala reservada, mas fora de sua unidade de trabalho.

O tempo de cada entrevista foi em média de cento e vinte minutos, dando-se liberdade a entrevistada para extrapolar este tempo.

A forma de registro das entrevistas foi a gravação em fita magnética $(\mathrm{k}-7)$, sendo a duração total dos depoimentos de 20 (vinte) horas. Garantido o sigilo, a pesquisadora transcreveu as fitas imediatamente apos as entrevistas.

\footnotetext{
* Utilizou-se a terminologia Corpo Social para designar o conjunto de pessoas que vivem em certa faixa de tempo e espaço, seguindo normas comuns, ao invés de universo ou população, porque este tempo adequa-se mais ao estudo do materialismo histórico, BERBECHKINA et al ${ }^{7}$

** HILTQN JAPIASSU” define multidisciplinaridade como “a gama de disciplinas que propomos simultaneamente, mas sem fazer aparecer as relações que podem existir entre elas"
} 


\begin{tabular}{l|}
\hline UNIDADES DE \\
REGISTRO OU \\
RECORTE DAS \\
ENTREVISTAS \\
\hline
\end{tabular}

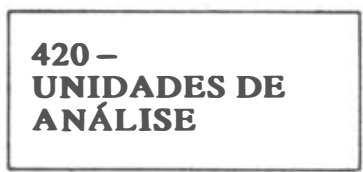

04

CATEGORIAS

\section{GRUPO $\longrightarrow$ GRUPO $\longrightarrow$ GRUPO $\longrightarrow$ GRUPO}

\section{RESULTADOS}

- O Perfil dos Atores Sociais em Relação àos Dados Pessoais

O grupo em estudo é constitúdo em maior parte por mulheres jovens, sendo $59 \%$ na faixa etária de 25 a 34 anos, na proporção de $44 \%$ tanto para solteiras como para as casadas. $76 \%$ moram com a famnia, independente da situação conjugal já que ấ inclui marido e/ou filhos, pai e/ou mãe e/ou irmãos. Das enfermeiras solteiras apenas $8 \%$ moram sozinhas; as demais ou moram com a famnia e/ou familiares (36\%). Como local de moradia, $85 \%$ residem na zona norte da cidade.

Com relação a remuneração mensal 39\% ganham acima de 18 salários mínimos, sendo que destas apenas $14 \%$ têm mais de um emprego. A faixa salarial coincide com o tempo de exercício profissional, onde $35 \%$ têm mais de 10 (dez) anos de formadas.

Quanto ao número de salários mínimos recebidos e os motivos que levam as enfermeiras a trabalhar, percebe-se que elas entram na composição econômica da casa, ou para complementar o salário da familia (41) mas poucas vezes de forma vital (18). O dado que mais nos chamou a atenção é a importância dada pelas enfermeiras à sua independência financeira e satisfação pessoal, mesmo que aliados a fatores como complementação salarial ou sustento da família (107).

CATEGORIA 1: - VIDA EM FAMfLIA

SUB-CATEGORIAS: • Constituição Familiar

- Identificação e Poder Decisório

- As Relações Intra-familiares

- As Relações Extra-familiares

- Dicotomia Meninos x Meninas

Verificou-se nos resultados deste estudo que as enfermeiras provém de famnlias grandes, em média superiores a seis componentes, sendo as mães consideradas "do lar" e tendo cursado até o primeiro grau. As filhas não seguem o mesmo padrão, obedecendo a regra geral do País em compor núcleos familiares menores, comprovando a tese de que o nível de instrução da mulher e sua atividade profissional têm uma relação inversa ao número de filhos. (SAMARA ${ }^{22}$ )

A influência da familia no desenvolvimento da personalidade das enfermeiras em questão se relaciona a "figura" do pai, o qual exerce o pátrio poder instrumental na famnia, isto $e$, gerador da economia, das relações sociais e na autoridade com os filhos, enquanto a mãe colabora nas decisōes relativas a educação escolar, doméstica, integrativa-afetiva. (CHODOROW'1)

As relações entre pais e filhos foram pautadas na obediência absoluta, sendo a escola a continuação da casa e manutenção das relações de dominação/submissão, apenas alterando-se na adolescência quando a menina-mulher busca os proprios espaços e rompe com as estruturas familiares. (BELOTTI ${ }^{6}$ )

\section{CATEGORIA 2: - DESVENDANDO \\ A ENFERMAGEM \\ SUB-CATEGORIAS: • A Descoberta \\ - A Escolha \\ - A Percepção da Famnlia quanto a Escolha \\ - O Contato com a Realidade Profissional}

O desejo de ser enfermeira é acoplado à necessidade de melhoria salarial, ascenção profissional, aquisição de status e forma de sair do jugo familiar.

A ideologia de servir e de cuidar do outro, delinea-se desde a infância na relação familiar e social e na interiorização de valores e exteriorização de hábitos de vida, através do contato com a doença, com os afetos familiares, com os esterétipos das profissões femininas e com a idéia romântica do que seja a enfermagem. (LIMA ${ }^{17}$ )

As famílias das enfermeiras, embora orgulhem-se da escolha, demonstram explicitamente o desejo de que estas usem-na como trampolim para outras profissões de maior prestígio, com ênfase na medicina. $\mathrm{O}$ diploma universitário é considerado como uma marca de distinção social, já que estas descedem de familias com menor poder aquisitivo e com pouca formação universitária. (MIRANDA, SAUTHIER ${ }^{20}$ )

O contato com a realidade profissional é mancante em vários aspectos: o primeiro salário é percebido como a representação viva de uma vitória, a abertura das portas da independência, embora se saiba que independência financeira não é sinônimo de autonomia. Preocupam-se com o desempenho técnico que lhes $\varepsilon$ exigido nas instituições hospitalares, para o.qual sentem-se muitas vezes inseguras e despreparadas, evidenciando assim a dicotomia entre o paradigma acadêmico e a realidade das instituições de saúde.

\section{CATEGORIA 3: - AS RELAÇŌES SOCIAIS NA ENFERMAGEM \\ SUB-CATEGORIAS: $\bullet$ O Masculino x O Feminino \\ - A Ordem Hierárquica \\ - A Enfermagem Tecnificada $x$ Enfermagem Edificante \\ - Mobilização Política}

No discurso das enfermeiras evidencia-se a ausência da dimensão objetiva da arte da enfermagem. A materialidade da vida doméstica de onde decorre a inspiração de muitas, anula este aspecto fundamental do exercício da enfermagem, privilegiando 
as dimensōes técnicas e tecnologicas, secundarizando os aspectos de criação e de sensibilidade inerentes à profissão.

Os estereótipos sexistas internalizados desde a infância determinam tanto a escolha profissional feminina, quanto a presença de atitudes de inferioridade e depreciação da própria enfermeira diante do sexo oposto, quer se ja na relação com os médicos, com os enfermeiros e com os demais profissionais do sexo masculino. O agir das enfermeiras reflete a socialização desta para exercer os papéis tradicionais femininos em simbiose com o exercício profissional. (LA$\mathrm{NA}^{15}$ ).

No exercício diário da enfermagem, as enfermeiras em questão têm dificuldade para acreditar em si próprias e para exercer o poder decisório, considenrando o homem mais preparado para tal, mesmo que em função dos estereótipos como "o menino sabe mais que a menina", "o homem manda melhor que a mulher" etc. Alêm disso, estas não estão mobilizadas politicamente nem a nível individual e/ou grupal dentro e fora da instituição, o que dificulta e as enfraquece na luta pelos seus direitos e na construção de uma enfermagem transformadora que atenda às necessidades da porção da sociedade que dela necessita. (BEAUVOIR $^{5}$ ).

A formação familiar e social tem influência direta na vida profissional das enfermeiras, tanto na relação com a equipe de saúde como com os clientes, evidenciada pelo espírito de colaboração, forte senso de responsabilidade e respeito a hierarquia.

$\mathrm{Na}$ relação com os subordinados aparece uma tendênica de agir pela dominação, contribuindo assim para garantir a sua continuidade, através da atuação como controladora da força de trabalho, invertendo a situação identificada em sua socialização, passando de oprimidas a opressoras.

$\mathrm{O}$ cuidado com o cliente em geral é permeado pelas atitudes de "deve fazer", cabendo a decisão final ao médico, embora já se perceba um vislumbre de uma prática de enfermagem mais edificante sob o ponto de vista ético e igualitário, permitindo ao cliente participar e decidir sobre o cuidado que deseja receber. (BARNES ${ }^{4}$ ).

\section{CATEGORIA 4: - OS ESPAÇOS DOMESTICOS E PÚBLICO}

SUB-CATEGORIAS: • A influência da Famnlia na Vida Profissional

- Repetindo Comportamentos

- A Empregada da Casa e a Empregada da Rua

A repetição de comportamentos domésticos vivenciados na famnlia se dá pela preocupação com a ordem, disciplina e organização, identificado no papel de "gerentes do hospital", onde o cumprimento do dever é prioritário, onde adquire um relativo poder.

A dupla e/ou tripla jornada de rabalho é uma constante na vida das enfermeiras, considerando a significância dos resultados quanto ao número de empregos, cabendo-lhe tamberm a responsabilidade pelo cuidado da casa e dos filhos, embora algumas obtenham a ajuda da mãe e/ou da empregada doméstica para tanto. Âs atividades domésticas já estão incorporadas como de sua responsabilidade, pouco compartilhadas com o marido/companheiro e quando acontece, não se dão de forma homogênea e igualitária. Também identifica-se que o poder decisório no campo doméstico, ocorre quando os atores sociais detém o poder econ仑́mico na famnlia, assumindo assim as decisões sobre a utilização da renda salarial. (MICHEL ${ }^{19}$ ).

Há indícios de transformações sociais nessas relações de gênero percebidas como parte do cotidiano, mas sua evolução depende de mudanças profundas no comportamento da sociedade como um todo.

A desigualdade não é uma condição necessária das sociedades, mas um produto de cultura e como tal, passível de mudança. A observação da desigualdade sexual em si possui significados diferentes em lugares diferentes, e as modificações nos papeis e poderes sociais nos status públicos e nas definições culturais estão vinculadas a estas desigualdades e seus tempos próprios de mudança. (BADINTER ${ }^{2}$ ).

\section{CONSIDERAÇÕES FINAIS}

Este estudo teve como objeto central a análise da mulher-enfermeira, a partir da reconstrução da estrutura familiar, avaliando os padrões de comportamento femininos daí advindos, e freqüentemente aceitos, sem questionamentos.

Pretendeu-se investigar não apenas a história formal, mas, principalmente a história pessoal, que juntas compõem o coletivo social, na medida que vincula-se a evolução da familia com a sociedade e deve modificar-se na medida em que esta última se modifique.

Examinamos a literatura específica de enfermagem encontramos poucos estudos sobre a correlação das relações familiares e sociais com a enfermeira/mulher, necessitando fundamentar esta abordagem em outros estudiosos das ciências sociais.

O materialismo historico forneceu o instrumental necessário para o entendimento dos processos culturais e históricos na formação da famnlia, estrutura e progresso social, bem como, permitiu o resgate e discussão da enfermagem no contexto de profissão historicamente feminina.

$\mathrm{O}$ método quantiqualitativo utilizado moetrou-se adequeado para aliar a precisão e objetividade dos resultados à subjetividade da analise de conteúdo das idéias expressas, a fim de facilitar o entendimento das influências familiares e sociais na escolha e exercício da enfermagem.

Partindo da análise literária verificou-se a existência da famnlia patriarcal no que concerne as relaçōes familiares, tendo cada elemento um papel determinado neste contexto. Os laços fraternos são valorizados como fundamentos determinantes da vida de cada um dos atores sociais tanto nos aspectos positivos como negativos. A inserção da mulher nas universidades, no mercado de trabalho e na política mostra-se como o caminho de escolha para estabelecer uma nova estrutura nas relaçōes familiares e sociais.

Envolve as questões familiares e sociais que influem na escolha e exercício profissional pretende indicar tanto os problemas como algumas soluções reflexivas para a questão da enfermagem enquanto profissão predominantemente feminina.

$\mathrm{O}$ futuro das relações homem-mulher, enfermeira-enfermeiro, enfermeira(o)/equipe de saúde apresenta uma tendência transformadora positiva no decorrer da história. Embora a rigidez patriarcal ainda 
subsista, algumas ruturas nos papéis familiares são indícios propulsores destas transformações emancipadoras da humanidade.

Finalizando, acreditamos deixar um desafio que amplie o leque de idéias para restaurar e reestruturar a

\section{REFERÊNCIAS BIBLIOGRÁFICAS}

ALQÂNTARA, Glete. A Enfermagem moderna como categoria profissional: Obstáculos à sua expansão na sociedade brasileira. Ribeirão Preto, Universidade de São Paulo, Escola de Enfermagem de Ribeirão Preto, 1966, p. 08 .

2 BADINTER, Elizabeth. Umé o Outro. 4 ed., Rio de Janeiro: Nova Fronteira, 1986. p. 139.

3 BAPTISTA, Sueli de Souza. Produção cientffica da pósgraduação em Enfermagem da EEAN/UFRJ. Enfermagem. Rio de Janeiro: Ed. da UFRJ, Ano I (1):52-70, 1988, p. 56.

4 BARNES, Elizabeth. As relações humanas no hospital. Coimbra: Livraria Almedina, 1973, p. 81.

5 BEAUVIOR, Simone. O segundo Sexo. 6 ed. Vol. 2 - Rio de Janeiro: Nova Fronteira, 1980. p. 451.

6 BELO T TI, E.G. Educar para a submissão. 6 ed., Petrópolis: Vozes, 1987, p. 8.

7 BERBECHKINA, Z. et al. Que é Materialismo Histórico? Moscovo, Ediçōes Progresso, 1987, p. 7.

8 BRASIL. CONSELHO FEDERAL DE ENFERMAGEM. $O$ Exercicio da Enfermagem nas Instituições de Saúde no Brasil: 1982/1983. Conselho Federal de Enfermagem/Associação Brasileira de Enfermagem, Rio de Janeiro: 1985. p. 57.

9 CAS TRO, Ieda Barreira et al. Dificuldades na incorporação dos resultados de pesquisa na prática de enfermagem. Anais do 4- Seminánio Nacional de Pesquisa em Enfermagem. São Paulo: ABEn/CEPEN, 1985. p. 233.

11 CHODOROW, Nancy. Estrutura familiar e Personalidade enfermagem como profissão/considerando os papéis e as ações femininas relacionadas com a famnlia, lançando luzes em antigas concepções sobre a natureza da sociedade de enfermagem e fornecendo pontos de discussāo para novos estudos. feminina. IN: A Mulher, a Cultura, a Sociedade. Rio de Janeiro: Paz e Terra, 1979. p. 88.

12 CORADINI, Sonia Regina e Col. A profissional enfermeira frente às influências da evolução histórica da mulher. Rev.Bras.Enf., RS., 36:246-254, 1983, p. 253.

13 GRELA, Cristina et al. Mujeres e Iglesia, Sexualidad y aborto en America Latina. México, Distribuiciones Fontamara, S.A., 1989. p. 69.

14 JAPIASSU, Hilton. Interdisciplinaridade e patologia do saber. São Paulo: Imago, 1976. p. 73.

15 LANE, Silvia T.M. O processo grupal. IN: Psicologia Social: $O$ homem em movimento. 7 ed., São Paulo: Brasiliense, 1989, p. 86.

16 LARGUIA, Izabel. El feminismo en Argentina aún no se considera con un movimiento polftico. Mujer/Fempress. (100/101):39, fev./mar., 1990.

17 LIMA, Ma José. Relato das Aplicaçōes Práticas das Teorias de Boaventura Souza Santos em Oficinas de Criatividade e Sensibilidade com Enfermeiros para fazer a trnsição da Enfermagem Tecnificada para a Enfermagem Edificante. 1. Congresso Luso-Afro-Brasileiro de Ciências Sociais. Coimbra, julho, 1990, mimeo. p. 7.

18 MICHEL, Andre. Não aos estereótipos. Vencer o sexismo nos livros para crianças e nos manuais escolares. São Paulo: UNESCO, 1989, p. 21-26.

19 MICHEL, Andre. Sociologia da Famplia e do Casamento. Porto, Portugal, Ed. Rés, 1983. p. 227.

20 MIRANDA, Cristina M.D.L., SAUTHIER, Jussara. Evasão:um estudo preliminar. 1989, mimeo. p. 7. 